Old Dominion University

ODU Digital Commons

Management Faculty Publications

Department of Management

2012

\title{
What Are The Correlates of Interdisciplinary Research Impact? The Case of Corporate Governance Research
}

\author{
William Q.Judge \\ Old Dominion University, wjudge@odu.edu \\ Thomas Weber \\ Old Dominiion University
}

Maureen I. Muller-Kahle

Follow this and additional works at: https://digitalcommons.odu.edu/management_fac_pubs

Part of the Business Administration, Management, and Operations Commons

\section{Repository Citation}

Judge, William Q.; Weber, Thomas; and Muller-Kahle, Maureen I., "What Are The Correlates of Interdisciplinary Research Impact? The Case of Corporate Governance Research" (2012). Management Faculty Publications. 6.

https://digitalcommons.odu.edu/management_fac_pubs/6

\section{Original Publication Citation}

Judge, W. Q. \& Weber, T. (2012). What are the correlates of interdisciplinary research impact? The case of corporate governance research. Academy of Management Learning \& Education, 11(1), 82-98. doi:10.5465/amle.2010.0191

This Article is brought to you for free and open access by the Department of Management at ODU Digital Commons. It has been accepted for inclusion in Management Faculty Publications by an authorized administrator of ODU Digital Commons. For more information, please contact digitalcommons@odu.edu. 


\title{
What Are the Correlates of Interdisciplinary Research Impact? The Case of Corporate Governance Research
}

\author{
WILLIAM Q. JUDGE \\ THOMAS WEBER \\ Old Dominion University
}

MAUREEN I. MULLER-KAHLE

Pennsylvania State University

\begin{abstract}
We explore the concept of interdisciplinary research impact and better understand what factors might be associated with it. Using the field of corporate governance research as a case study and linking our research impact concept to a novel measure of scholarly citation rates, we seek to understand why some corporate governance scholars are cited more than others. We first developed a comprehensive ranking of the top-100 scholars cited for their research in corporate governance and then compared that "high-impact" group with scholars who had published governance research that was not yet cited. We hypothesized that indicators from the social network perspective would be predictive of interdisciplinary research impact. Our data largely supported our hypotheses using this new and improved measure of research impact, and robustness tests also supported our results.
\end{abstract}

All scholars seek to publish their research and influence others through their research insights. When scholars publish their research, they are said to be "productive," particularly when that research is in great quantity over a limited period of time. However, "influence" or "impact" happens when a scholar's publication(s) is read and cited widely and over time by other scholars. When a scholar's research is highly cited, that scholor is known to do high-impact research. ${ }^{1}$ As such, a scholar's research impact can be defined as the ability of an individual to influence the thinking of other scholars by way of citations (Antonakis \& Lalive, 2008; Truex, Takeda, \& Cuellar, 2009; Woodside, 2009), and its nature and correlates are the focus of our work here.

In the initial sociology of knowledge literature, the focus was on understanding research productivity within a particular discipline. However, disciplinary research in the social sciences is increas-

${ }^{1}$ In this study, we used research impact and influence interchangeably. ingly criticized as pursuing irrelevant questions or providing inconsequential insights (e.g., Bartunek, 2007; Graffy, 2008; Lee, 1999; Lorsch, 2009). While some advocate reform within discipline-based paradigms, others recommend more interdisciplinary research in order to be more influential (e.g., Argyris, 1996; Jacobs \& Frickel, 2009; Wright, 2011). Here, we focus on the latter recommendation.

Interdisciplinarity ${ }^{2}$ is conceptualized in this study as communication and collaboration across academic disciplines, and interdisciplinary research is on the rise. One reason is that today it is much easier to read across disciplines due to online database searchers (Piotrowksi, Watt, \& Armstrong, 2010). However, another reason is that this type of research is seen as being more influential. For example, in a recent national survey of 1,353 college and university faculty in the United States, $70 \%$ agreed (strongly or somewhat) with the state-

\footnotetext{
${ }^{2}$ In this study, we make no distinction between interdisciplinary research with that of cross-disciplinary, multidisciplinary, and transdisciplinary research.
} 
ment that "interdisciplinary knowledge is better than knowledge obtained from a single discipline" (Jacobs \& Frickel, 2009). Also, there are now over 10,000 interdisciplinary research centers established in United States colleges and universities, many of which operate within the premier higher education institutions. Furthermore, the National Science Foundation established funding for interdisciplinary training programs for graduate research fellows in 2006. This trend is not limited to the United States, as European research is also pursuing interdisciplinary insights (Bruce, Lyall, Tait, \& Williams, 2004). Indeed, the new editors of the Journal of International Business Studies are repositioning this well-respected journal to become more interdisciplinary (Cantwell \& Brannen, 2011). The basic assumption behind many of these trends is that interdisciplinary research has greater impact than disciplinary research (Jacobs \& Frickel, 2009).

Unfortunately, there is little agreement as to what it means to be influential as a research scholar (Jarley, Chandler, \& Faulk, 1998). Perhaps the most general notion that underlies research impact is the publication count, since you can't be cited by others unless you are first published. As Worrell (2009: 127) states: "The Dean may not know very much about research, but at least she or he can count." Unfortunately, publication counts fail to consider the scientific impact, or overall quality of the knowledge created (McWilliams, Siegel, \& Van Fleet, 2005).

Since assessment of impact on business practices is very difficult to measure or observe, the most common metric used to assess impact is the number of citations by other scholars of a particular publication (Judge, Cable, Colbert, \& Rynes, 2007). Most recently, assessment of research impact has attempted to measure both the quantity and quality of scholarly output through such measures as the Hirsch Index, which is defined as the number of papers published with a citation number higher or equal to "h." Thus, a scholar who has an $h$ of 13 has 13 papers with at least 13 citations, and the higher the $\mathrm{h}$ the more impactful the scholar is (Antonakis \& Lalive, 2008).

As might be expected, there is even less understanding as to what the predictors of significant or impactful research might be (Daft, Griffin, \& Yates, 1987). Many scholars are content to list the most productive scholars in a particular discipline over a specified period of time in such disciplines as accounting (e.g., Mathieu \& McConomy, 2003); marketing (e.g., Robinson \& Adler, 1981); and economics (e.g., Medoff, 1996). Some recent studies have explored the relationship between single predic- tors, such as career life cycles (e.g., Chen, Gupta, \& Hoshower, 2006); gender (e.g., Maske, Durden, \& Gaynor, 2003); and doctoral program pedigree (e.g., Smith, Fox, Park, \& Lee, 2008). However, to our knowledge there has not yet been an integrated theoretical perspective used to explain research impact. Finally, there is virtually no research on how interdisciplinary research impact can be evaluated because all previous studies have focused on single disciplines, despite the fact that an increasing number of problems that confront business and society are interdisciplinary in nature (Cheng, Henisz, Roth, \& Swaminathan, 2009).

Consequently, we attempt to fill several voids in the scholarly literature that deals with research impact here, using the interdisciplinary field of corporate governance as a case study. First, we develop and test a new and improved measure of research impact, which we call the "Research Impact Index." Some have argued that the Hirsch Index is the single best indicator of research impact (e.g., Prasad \& Prasad, 2009; Truex et al., 2009); we discuss its advantages and shortcomings and conclude that the sociology of knowledge literature can do better. Second, we advance social network theory to describe and explain why some scholars might be more influential in their interdisciplinary research than others. Notably, almost all the social network predictors are supported by our data despite the fact that this theoretical perspective has never, to our knowledge, been used before to explain research impact. Finally, using our new research impact measure, we develop a listing of the 100 most influential research scholors in the field of corporate governance. As such, our study provides a template for evaluating scholars, departments, and even universities for assessing research impact beyond cruder productivity measures, such as publication counts or publications in top-tier journals.

\section{THEORY DEVELOPMENT}

We begin with an exploration as to just what research impact is: We explain how interdisciplinary research differs from discipline-based research, provide a brief overview of social network theory, and build several hypotheses within this theoretical perspective to describe and explain interdisciplinary research impact.

\section{The Nature of Scholarly Research Impact}

McWilliams and colleagues (2005) argue that research productivity is the precursor to research impact, and it can be conceptualized as scholarly 
output per unit of input. As can be seen in Table 1, previous studies of research productivity have tended to focus only on the numerator or outputs of the research productivity assessment. In general, most studies examine the number of publications produced by a particular scholar within what is perceived to be a select set of top-tier publications in the field over a 5-, 10-, or 20-year period. As such, previous literature has generally focused on the quantity of research produced within what are perceived to be the highest quality outputs.

While this literature is interesting and useful, it has some significant limitations and biases. The first limitation is that these estimates ignore all but a select set of research outlets. As such, a fairly wide range of research scholarship is ignored, and its impact on knowledge generation is not captured (Adler \& Harzing, 2009; Meho \& Yang, 2007). The second limitation is that these proxies fail to consider the actual impact of the research by assuming that the research is influential simply because of its publication in a top-tier publication. As such, they fail to consider whether the research is read or cited in subsequent work. Notably, previous research has shown that the most cited $15 \%$ of articles in top-tier management journals receive over $50 \%$ of all citations, and $20-40 \%$ of all published articles in those same journals receive no citations (Woodside, 2009). Similarly, over $50 \%$ of marketing citations emanate from less than $3 \%$ of all marketing scholars (Robinson \& Adler, 1981).

In addition, many studies have a third limitation in that the previous research has failed to consider how multiple authors contribute to a study; therefore, contributions by first authors may be overestimated, and contributions by coauthors may be underestimated. Finally and perhaps most important, these measures are typically cumulative in nature, so they bias the estimate for those who publish their work early in the study period while underweighting the contributions of scholars who produce work later in the study period.

For all these reasons, there is a need for an improved measure to capture the research impact of an individual scholar. Some argue that the Hirsch Index is an improvement over more typical publication or citation counts, as it simultaneously considers both the quantity (number of papers published) as well as the quality (citations of those papers). In addition, it is fairly easy to compute. However, it has been criticized for ignoring the multiple author issue (e.g., Prasad \& Prasad, 2009).

TABLE 1

Chronological Listing of Previous Bibliometric Studies of Business Faculty Research Productivity

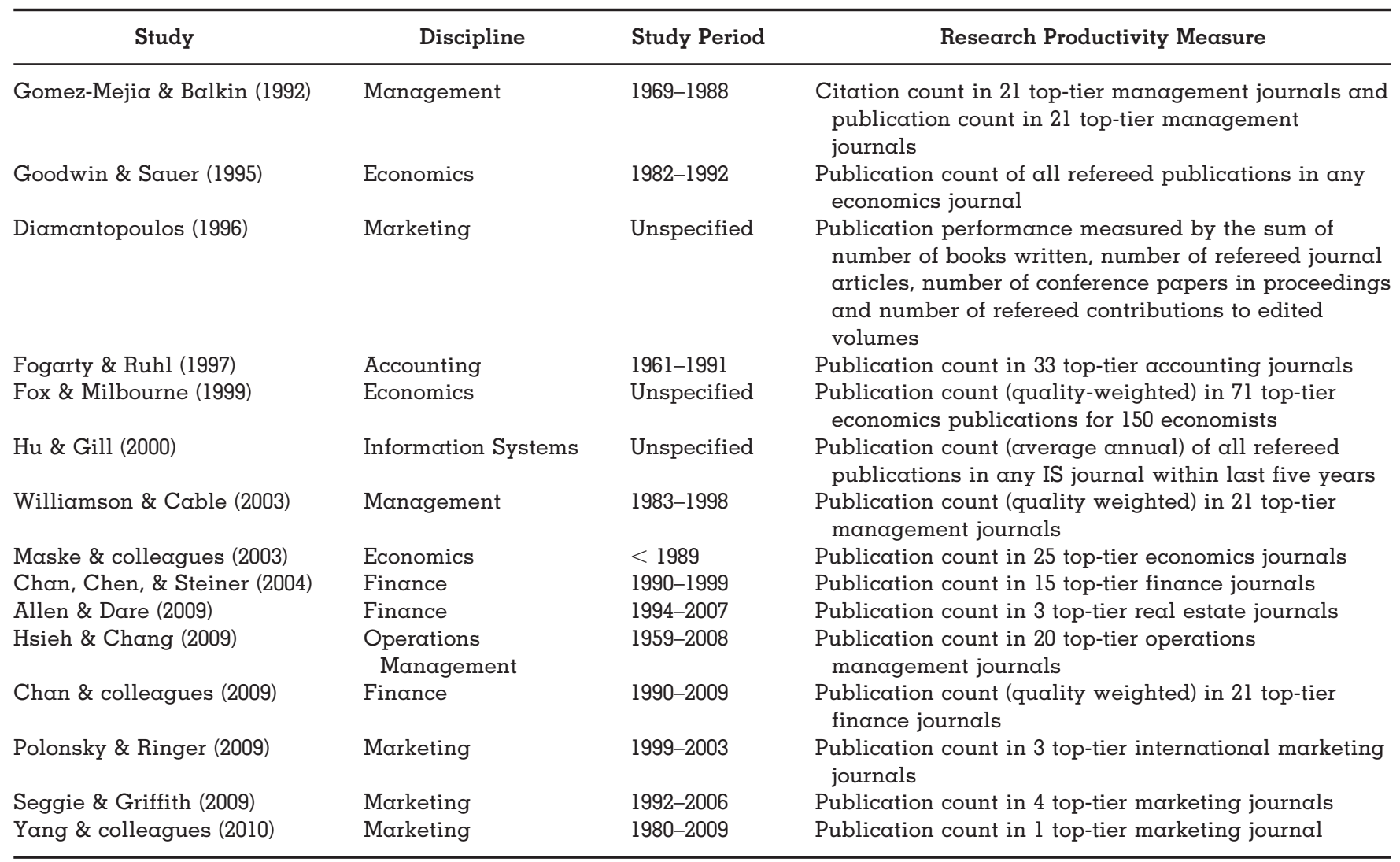


Furthermore, it has been shown to be biased toward well-established researchers by ignoring the year of the publication (e.g., Antonakis \& Lalive, 2008). Finally, and most important for this study, the Hirsch Index has been criticized as being inadequate for comparing research impact across disciplines due to different citation patterns (Truex et al., 2009). As such, there is a need for a better measure of interdisciplinary research productivity than the Hirsch Index.

While the goal of all scientific research is to increase knowledge, this goal is rather amorphous. Since citations by other scholars are an important indicator of the impact of the new knowledge on scholarly thinking (Judge et al., 2007), the aggregate citations earned by an individual scholar per year can be a useful indicator of research impact because this process is not biased toward older publications. This is particularly true if the study period is not limited to an arbitrarily short time period or if the citations are not limited to a select set of journals. Hence, this conception of a particular author's aggregate citation rate per year during a 52-year study period (i.e., 1956-2008) is what we use here for our exploration of research impact.

\section{Disciplinary Versus Interdisciplinary Research Productivity}

Previous research has examined the antecedents or effects of research productivity for the disciplines of accounting (e.g., Fogarty \& Ruhl, 1997; Manning \& Barrette, 2005; Mathieu \& McConomy, 2003); finance (Chan, Chen, \& Fung, 2009); economics (e.g., Barbezat \& Hughes, 2001; Davis, Huston, \& Patterson, 2001; Fox \& Milbourne, 1999; Goodwin \& Sauer, 1995; Hammermesh \& Oster, 2002; Maske et al., 2003; McDowell \& Smith, 1992; Medoff, 1996; Moore, Newman, \& Turnbull, 2001); information systems (e.g., Gallivan \& Benbunan-Fich, 2007; Hu \& Gill, 2000); management (e.g., Bedian, Cavazos, Hunt, \& Jauch, 2010; Boyd, Finkelstein, \& Gove, 2005; Chermack \& Lynham, 2002; Daft et al., 1987; Jarley et al., 1998; Williamson \& Cable, 2003); marketing (Robinson \& Adler, 1981); operations (e.g., Smith et al., 2008); and sociology (e.g., Burris, 2004).

A few studies have begun to look at the antecedents and effects of research for multiple disciplines, such as the general productivity of business faculty (e.g., Chen et al., 2006) and university faculty (e.g., Pfeffer \& Langton, 1993). To our knowledge, only a handful of studies have previously attempted to explore a specific area of interdisciplinary research. One of the first was a ranking of business ethics scholars by Sabrin (2002). Scholars from a wide variety of disciplines read, cite, and collaborate on business ethics topics, so it clearly is an interdisciplinary subject. Unfortunately, this study did not attempt to explore what might be the antecedents of research impact for this type of scholarship.

More recently, Xu, Yalcinkaya, and Seggie (2008) sought to identify who the most prolific international business researchers were, based on their examination of publications in six leading international business (IB) journals. Once again, this study was largely descriptive, with no exploration of the antecedents of research productivity. Similarly, Treviño, Mixon, Funk, and Inkpen (2010) examined research productivity in IB, and it was evaluated using a wider range of journals over a longer period of time (1996-2008). Although these results are notable, this study also was largely descriptive in nature. Finally, Bergh, Perry, and Hanke (2006) took a different route and examined the determinants of article impact for studies appearing in Strategic Management Journal using a disparate array of previous findings.

Interdisciplinary research is clearly different from discipline-based research (Cheng et al., 2009). Interdisciplinary researchers must not only read and be conversant with their own discipline's understanding of the phenomena in question, but they must also read and be conversant with other disciplines. Furthermore, interdisciplinary scholars must work across disciplinary boundaries in order to be effective, and this breadth of activity can hinder the in-depth understanding that is often sought in disciplinary studies (Zahra \& Newey, 2009). Also, it often requires becoming fomiliar with multiple disciplinary preferences for certain methodologies as well as unconscious assumptions about what "good science" might constitute (Jacobs \& Frickel, 2009). In sum, we posit that it takes a different set of skills to publish interdisciplinary research that is read and cited by scholars from other disciplines, and that those skills can best be understood by studying the scholars' social network. Consequently, we turn to social network theory to describe and explain interdisciplinary research impact.

\section{Brief Overview of Social Network Theory}

Social network theory views social systems in terms of nodes and ties. The nodes are the social entities of interest within the social system (e.g., individuals, groups, organizations, and even societies); and the ties are the relationships between the social entities. The fundamental insight of this theory is to focus on the relationships between 
social entities rather than the specific attributes of the social entity to explain perceptions, behaviors, and social outcomes. Barnes (1954) was one of the first social scientists to study networks between and within social systems.

Social network theory has been used to examine how social relationships influence interpersonal power (e.g., Labianca \& Brass, 2006); entrepreneurship outcomes (e.g., Greve \& Salaff, 2003); negotiation results (e.g., Money, 1998); discrimination events (e.g., Friedman, Kane, \& Cornfield, 1998); supply chain logistics (e.g., Carter, Ellram, \& Tate, 2007); and even regional innovation (e.g., Fleming, King, \& Juda, 2007). Social network analysis is a set of statistical techniques for analyzing the nature of the ties between the nodes within a particular social system.

There has been some recent research on the relationship between social network predictors and the research productivity of scientists. For example, Carillo, Papagni, and Capitanio (2008) found that several social network predictors were systematically related to the research productivity of social and natural scientists from five Organization for Economic Cooperation and Development (OECD) countries. Similarly, Leahey (2007) used social network analysis to help explain research productivity for faculty operating in Research $\mathrm{I}^{3}$ universities throughout the United States. In sum, by examining attributes associated with the social network of social scientists, we will better understand interdisciplinary research productivity.

\section{Social Network Correlates of Interdisciplinary Research Impact}

It is instructive to begin by examining why scholars attempt to create and publish research. Silver (2008) notes that there are a wide variety of motivations, which include (1) self-fulfillment, (2) solving problems for practitioners, (3) peer recognition, (4) tenure and promotion expectations, (5) improved teaching, (6) an opportunity to train graduate students, (7) funding for further research, and (8) spinoff potential for textbooks or consulting. All these reasons for producing research are influenced by the social network in which the scholar operates. This suggests that the social network perspective may be influential in explaining research impact. And for interdisciplinary research, social networks

\footnotetext{
${ }^{3}$ A 'Research I' university was a category previously used by the Carnegie Classification of Institutions of Higher Education to indicate those universities that engaged in extensive research activity. In 1994, there were only 59 Research I universities in the United States.
}

are especially important because of the complexity of such fields of study.

Social networking factors encompass the structure of personal and professional relationships that an individual has with others (Carpenter, 2009; Judge et al., 2007). These observers essentially argue: "It isn't what you know, it is who you know that matters." Science is increasingly a collaborative enterprise, so who you train with and collaborate with can make a difference in your subsequent research record. Illustrating this fact, Daft and colleagues (1987) found that the greater the collegial interaction, the more likely that the scholar produced "significant" research. The following factors attempt to capture the impact of social networks to explain research impact.

\section{Cocuthorship Frequency}

There has been a substantial increase in coauthored articles in recent years. For example, Heck and Zaleski (1991) demonstrated that the incidence of coauthorship has increased from about $15 \%$ of total articles in 1969 to about 35\% in 1989. One of the primary reasons for this has been the "shrinking of distance" due to new information and communication technologies (Hammermesh \& Oster, 2002). A related reason might include the social networking benefits of such collaborations.

When a research study is coauthored, the authors can focus in their area of comparative advantage and reduce the individual time invested in any one article. In addition, the scholars' social network comes into play through the utilization of advice, specialized expertise, and access to critical resources (Belliveau, 2005). Illustrating this relationship, Maske and colleagues (2003) found that the incidence of coauthored articles was positively related to subsequent research productivity for economists. Furthermore, Allen and Dare (2009) reported a positive relationship between coauthorships and research productivity for finance scholars. And Yang, Jaramillo, and Chonko (2010) found a positive relationship between coauthored articles and research productivity for sales and marketing scholars. Assuming that these same social networking dynamics apply to research impact, this literature and logic suggests the following relationship:

Hypothesis 1: The frequency of coauthored articles published by a scholar is positively associated with interdisciplinary research impact. 


\section{Doctoral Program Pedigree}

Aside from gender, perhaps the most researched factor used to explain research productivity is the prestige of the doctoral program in which the individual was trained (Chan et al., 2009). It is fairly well established that "academic pedigree" is a strong determinant of subsequent research productivity. Indeed, some scholars even pejoratively refer to this networking phenomenon as an "academic caste system," whereby exclusive social networks are established and protected (Burris, 2004).

Doctoral program prestige has been found to be associated with research productivity in economics (Fox \& Milbourne, 1999; Goodwin \& Sauer, 1995); management (Bedian et al., 2010; Williamson \& Cable, 2003); accounting (Fogarty \& Ruhl, 1997); finance (Chan et al., 2009); and information systems (Hu \& Gill, 2000). When a scholar trains at a prestigious institution, he or she is exposed to individuals who occupy powerful positions within the field of study. This exposure can open the doors to exclusive social networks and rare career opportunities. This literature and logic behind the social networking advantages of doctoral program prestige suggest the following relationship:

Hypothesis 2: The prestige of the doctoral program in which the scholar trained is positively associated with interdisciplinary research impact.

\section{English Language Native}

Communication ties are central to social network theory (Burt, 1982), and the actor's native language is central to communication patterns. English is the predominant language used for the global research enterprise, particularly in the social sciences. This fact clearly places non-native English speakers at a competitive disadvantage to native speakers. As such, the scholar's native language can pose a social networking advantage in their subsequent research productivity.

There is considerable evidence to support the notion that native English speakers have competitive advantages over non-native speakers. For example, in examining the research productivity of finance scholars throughout Europe, English language natives dominated the rankings (Chan et al., 2009; Chan, Chen, \& Steiner, 2004). In a systematic study of the research productivity of marketing scholars throughout the world, English language natives based in North America dominated the rankings (Polonsky \& Ringer, 2009). And in a worldwide assessment of production and operations management research productivity, scholars from the United States, United Kingdom, and Canada (all English-language countries) dominated the rankings (Hsieh \& Chang, 2009). This suggests the following hypothesis:

Hypothesis 3: If the scholar is an English language native, then the scholar will have more of an advantage in interdisciplinary research impact than scholars who do not speak English as their native tongue.

\section{National Differences}

Social networks operate at a societal level as well. After World War II, the United States invested heavily in its colleges and universities. This investment yielded some of the premiere institutions of higher education throughout the world. While other nations devote a considerable amount of their investment capital in alleviating poverty (Dao, 2004), the world's largest economy and richest nation has wealth available to focus on higher education. As such, being an academic in the United States can confer social network advantages above and beyond the English language advantage.

Accompanying this premiere status includes high and rising standards of research scholarship for American scholars. As a result, institutions in the United States often attract the world's premier academics and are the best positioned to produce highly impactful research. For example, the 2009 Academic Ranking of Worldwide Universities listed the United States as having 17 universities out of the top 20 (Shanghai Jiao Tung University, 2010). And in a wide variety of worldwide assessments of disciplinary research productivity, the United States is often at the top (e.g., Chan et al., 2004; Hsieh \& Chang, 2009; Polonsky \& Ringer, 2009). Of course, alternative explanations for this dominance argue that there is a U.S.-centric bias in the publication and citation arena (Gallivan \& Benbunan-Fich, 2007). Regardless of the reason, this literature and logic suggest that U.S.-affiliated scholars have a social networking advantage:

Hypothesis 4: If the scholar is affiliated with an academic institution based in the United States, the scholar will be more likely to be impactful in his or her interdisciplinary research than those who operate outside of the United States. 


\section{Doctoral Program Affiliation}

A final potential social networking predictor of interdisciplinary research productivity may be the presence or absence of a doctoral program available to a particular scholar. When a social scientist has access to the social network of a doctoral program, the scholar's teaching mission often becomes more directly aligned with the research mission of the school in which the scholar operates. In addition, the interdisciplinary researchers often have access to highly trained research assistants, whereas other scholars who do not operate in this type of environment may be limited to lesser trained or no research assistants. Finally, the ability to read each other's papers, participate in interdisciplinary research colloquiums, and tap the rich and diverse theoretical and methodological expertise that are necessary for operating doctoral programs can all lead to higher levels of interdisciplinary research productivity. Therefore, being connected to a doctoral program may also be correlated with research productivity.

Once again, there is some empirical research in previous disciplined-based studies to support this notion. For example, Daft and colleagues (1987) found that affiliation with a doctoral program was positively associated with the production of significant research in the management disciplines. Pfeffer and Langton (1993) later found that social resources associated with a doctoral program were positively associated with research productivity, measured as publication counts. Morrisey and Cawley (2007) reported that the doctoral programs help to explain research productivity in economics. And $\mathrm{Hu}$ and Gill (2000) found a positive relationship between doctoral program affiliation and research productivity in the accounting discipline. Hence, this leads to our fifth and final hypothesis: Hypothesis 5: If the scholar works within a school that contains a doctoral research program in their discipline, they are more likely to be impactful in their interdisciplinary research than those who do not have this social networking advantage.

\section{METHODOLOGY}

\section{The Interdisciplinary Field of Corporate Governance}

Corporate governance is an interdisciplinary field of study that seeks to understand how corporate power is directed in socially beneficial ways within a national or global economy. The field of corporate governance is arguably one of the most interdisciplinary fields of study in the social sciences today, with active research conducted by social scientists in management, finance, economics, accounting, sociology, political science, and legal studies (Judge, 2009).

In addition to its interdisciplinary nature, corporate governance is increasingly international in nature. Early literature focused on the antecedents and effects of corporate governance in the United States and the United Kingdom. However, recent research is much more multinational and international in its focus, as the global economy continues to expand, and the economic dominance of the United States continues to wane (Judge, Filatotchev, \& Aguilera, 2010). As such, this field of study enables us to also explore the impact of native tongue and United States affiliation compared to other interdisciplinary fields of study. In sum, the field of comparative corporate governance serves as a case study for this particular empirical examination of the social networking relationships with interdisciplinary research productivity.

\section{Research Impact Measurement}

The study operationalized research impact in two ways. First, it was examined as a continuous variable. Our Research Impact Index captures the normalized citation rate value for each corporate governance scholar in the study. This variable was computed using the following equation:

$$
\text { Research Impact Index }=\sum_{n=1}^{A C} \frac{\mathrm{TC}_{n}}{\overline{N Y}_{n}}
$$

Where

$\mathrm{AC}=$ Article Count of corporate governance studies published by an author in all social science citation index (SSCI) rated journals;

$\mathrm{TC}_{n}=$ Total Citations per corporate governance article from 1956 to 2008;

$\mathrm{NY}_{n}=$ Number of Years of corporate governance articles published, or 2008 - publication year +1 ;

$\mathrm{NA}_{n}=$ Number of Authors per corporate governance article to account for multiple authors.

We believe that this particular measure is much more reliable and valid than previous measures used in the literature for several reasons. First, many previous research productivity studies have simply used simple counts of articles published (e.g., Bazley \& Nikolai, 1975; Brown \& Gardner, 1985; Chermack \& Lynham, 2002; Cole \& Cole, 1967; Davis et al., 2001), but this approach does not consider whether the article is cited or not and to what degree it is cited. As Leahey (2007) points out, when 
scientific fields are just getting started, publication or citation counts suffice. However, as a scientific field matures, more nuanced conceptualizations of research productivity need to be considered.

Second, other research impact studies have failed to control for the number of years for which an article could be cited (e.g., Fox \& Milbourne, 1999; Medoff, 1996; Sabrin, 2002). As such, this creates a potentially unfair bias for older publications. Hence, our measure captures the citation rate per year, rather than overall citations. Third, other research productivity or impact studies have neglected to consider the impact of multiple authors (e.g., Bazley \& Nikolai, 1975; Brown \& Gardner, 1985; Fogarty \& Ruhl, 1997). As such, this creates a potential bias against single-authored works. Consequently, our measure attempts to parse out the individual author's contribution by dividing the citation rate by the number of authors involved with the study.

Finally, we consider all citations in all relevant SSCI publications from 1956 to 2008, not just a select listing of "top" journals (e.g., Chan et al., 2009; Jarley et al., 1998; Manning \& Barrette, 2005). As a result, we believe that our Research Impact Index is much more comprehensive than previous studies.

In addition to this new index, we created a derivative dichotomous variable which we called, Research Impact Group. This dummy variable takes the value of " 0 " for those scholars whose works have not been cited, and a "l" when the scholar is a member of the highly cited group. With this approach, we could examine both continuous and categorical research impact effects.

\section{Sampling Design}

The beginning year of the study period was 1956 because the earliest data in the Social Science Citation Index (SSCI) were from that year. The end of the study period was 2008 to ensure a full year of citations since the data were collected in 2009. Consequently, our study period was 52 years. The following categories for the 509 journals within the SSCI were used to determine which journals to include in the interdisciplinary searches: Business; Finance; Economics; Ethics; Law; Management; and Public Administration.

Next, we sought to identify all corporate governance articles published within this 52-year time period for these 509 journals. The following search terms were used to identify all of the articles during our study period of 1956 until 2008: (1) Corporate Governance, (2) Board of Directors, (3) Ownership
Structure, (4) Legal System and (5) Market for Corporate Control. This set of search terms yielded 6,389 corporate governance articles from 421 journals, which constituted our master article list. The SSCI calculated the total citations for the time period over which the search request was run. Calculations were made to determine one scholar's article credit based on the total citations, age of the article, and the number of authors. Self-citations were not excluded because they have been found to have a minimal effect on rankings (Cronin \& Meho, 2006).

The result of this broad search was an overall population of 7,483 scholars who published interdisciplinary research on corporate governance in 421 separate social science journals. Interestingly, $2,140(28 \%)$ of the scholars were never cited for their research, which is consistent with previous literature. In contrast, $327(4.4 \%)$ of the scholars obtained more than $50 \%$ of the citations for their corporate governance research, which is a bit more concentrated than previous literature would indicate. As such, these statistics suggest that there is considerable variance in research productivity and impact in the field of corporate governance.

Although this list is limited by the journals available through SSCI, this approach offers a much more comprehensive review of the scholarly productivity than by limiting the search to just a few top-rated journals. Consequently, this approach gave each article's publication equal worth and is much more comprehensive, unlike many other previous research productivity studies (Adler \& Harzing, 2009; Gallivan \& Benbunan-Fich, 2007; Marsh $\&$ Hunt, 2006).

The next step was to take each article in the master list and split out the individual authors to create a normalized amount of citation credit for each author per article. The names were reviewed to combine names that referred to the same person, but were listed differently in the SSCI database (Adler \& Harzing, 2009). This number was summed to calculate the total citation "credit" each author received in order to rank the authors from most productive to least productive. One issue with this is that it is not possible to determine the actual contribution of each author to an article; therefore, a simple division by the number of authors was used (Garfield, 1977).

Within the SSCI database, all authors beyond the first three are identified as "et al." if there was a single author, that person received full credit for the citation. If there were two or three authors, each author received one-half or one-third credit, respectively. If there were four or more, each of the named authors received one-fourth of the credit 
(Brown \& Gardner, 1985; Medoff, 1996). As discussed previously, the credit for an article's citations was created by dividing the number of citations for an article by the number of authors. Because some of the articles had four or more authors, there are articles that only have $75 \%$ of citation credit in our master list. The citation credit was then normalized for each article by multiplying the average citations per year by the citation credit (Meho \& Sonnenwald, 2000). This normalized number was summed for each author who had more than one article. This research impact index was used to create the ranking of the top-100 scholars. As can be seen in Table 2, Professor Michael Jensen ranks no. 1 on the scholar list, with a research impact index of 119.41, and Professor Christion Leuz ranks no. 100 with on index of 11.72. As can be seen from this listing, there are a relatively wide variety of disciplines represented, which adds further validity to our claims that the field of corporate governance is truly interdisciplinary.

\section{Data Collection Procedure}

Once the summed list of authors was created, this listing was sorted by the total citation credit for each author. The goal of the study was to examine the social network characteristics of the top-100 cited authors and compare those characteristics to a random sample of 100 of the 2,140 authors who published corporate governance research, but were subsequently not cited in order to determine what antecedents differentiated these two groups of scholars. Unfortunately, we were only able to obtain curricula vitae (CVs) from 66 of the 100 top scholars. As a result, we collected an extreme variance sample of 66 cited and 66 uncited corporate governance scholars in order to understand what differentiates these two groups.

These CVs were then content analyzed to collect archival data for the analysis. One experienced coder analyzed all of the $132 \mathrm{CVs}$ in the study. Intercoder reliability was established by having another trained coder recode $10 \%$ of the $\mathrm{CVs}$ and then perform two intercoder reliability tests. The first test was a percentage agreement test, with results showing $87 \%$ agreement between coders. A second more rigorous test was performed using the Cohen's Kappa calculation, with results showing a score of .75, which is in the acceptable range for a study using content analysis (Landis \& Koch, 1977). When there was a discrepancy between the coders, they discussed the differences and a joint decision was made. Our final sample consisted of a matched paired design of 132 corporate governance scholars.

\section{Social Network Predictors}

We collected five variables from archival records that characterized the social network of the corporate governance scholar. The Coauthorship Frequency variable was measured as the number of coauthored articles counted on the CV divided by the total number of articles published also counted on the CV. The Doctoral Program Pedigree variable was operationalized as the existence of the PhDgranting institution's existence on the 2008 BusinessWeek or 2008 Financial Times top business school lists. This was a 0/1 categorical variable where a " 1 " indicated that the scholar received a $\mathrm{PhD}$ from an institution that was on at least one of the top business school ranking lists compiled by BusinessWeek and the Financial Times.

The English Language Native indicator was created by content analysis of the $\mathrm{CV}$ and searching the scholar's institution's website. This variable was set to " 0 " if any of the following conditions were met: (1) the scholar graduated from an institution based in a non-English speaking country, (2) his or her earliest works were in a language other than English, (3) the curriculum vitae mentioned the native language was not English, or (4) the scholar's website indicated another language was the native language. Otherwise, the variable took on the value of " 1 " to indicate the scholar was a native English speaker. The Academic Affiliation variable was derived from examining the location of the scholar's current university. This was a dummy variable where " 0 " indicated a United States location and "1" a non-U.S. location. Finally, the Doctoral Program Affiliation predictor was once again obtained from the scholar's $\mathrm{CV}$ and dummy coded as a " 0 " if the scholar's institution offered a doctoral program in his/her discipline and as a "l" if the scholar's institution did not. This variable was later verified by examining the academic institution's website for the presence or absence of a doctoral program.

\section{Control Variables}

Since there has been extensive previous research on disciplinary-based scholarship, we also attempted to control for other predictors of scholarship. Perhaps the most researched previous predictor of scholarly productivity is the Gender of the scholar. Previous research has attempted to ascertain if being a male confers an advantage over being a female, but the literature is largely equivocal (Chen et al., 2006; Fogarty \& Ruhl, 1997; Maske et al., 2003; McDowell \& Smith, 1992; Pfeffer \& Langton, 1993; Williamson \& Cable, 2003). Gender was 
TABLE 2

Listing of High-Impact Scholars in Corporate Governance Research During the 1956-2008 Period

\begin{tabular}{|c|c|c|c|c|c|c|c|}
\hline Rank & Name & Index & Discipline & Rank & Name & Index & Discipline \\
\hline 1 & Michael C Jensen & 119.41 & $\begin{array}{l}\text { Economics, Finance, } \\
\text { and Accounting }\end{array}$ & 51 & Steven N Kaplan & 16.61 & Economics \\
\hline 3 & William H Meckling & 67.38 & $\begin{array}{l}\text { Honorary Doctor of } \\
\text { Social Science }\end{array}$ & 53 & Elena Kagan & 16.50 & Law \\
\hline 4 & Rafael La Porta & 66.28 & Economics & 54 & Oliver Hart & 16.28 & Economics \\
\hline 6 & Lucian Arye Bebchuk & 62.34 & Law & 56 & David A Skeel & 15.90 & Law \\
\hline 7 & John C Coffee & 62.25 & Law & 57 & Douglas J Miller & 15.88 & Management \\
\hline 8 & James D Westphal & 54.99 & Management & 58 & Igor Filatotchev & 15.70 & Economics \\
\hline 9 & Bernard Black & 52.30 & Law & 59 & Michael Steven Weisbach & 15.70 & Economics \\
\hline 10 & Luigi G Zingales & 50.02 & Economics & 60 & Paolo F Volpin & 15.61 & Economics \\
\hline 11 & Stephen M Bainbridge & 40.91 & Law & 61 & John E Core & 15.07 & Accounting \\
\hline 16 & René M Stulz & 36.39 & Economics & 66 & Robert Parrino & 14.54 & Finance \\
\hline 17 & Edward Zajac & 36.34 & Management & 67 & Bruce M Kogut & 14.22 & Management \\
\hline 18 & Robert Vishny & 30.74 & Economics & 68 & I J Alexander Dyck & 14.16 & Economics \\
\hline 19 & Catherine M Dalton & 29.98 & Management & 69 & James M Nelson & 13.94 & Finance \\
\hline 20 & Jean Tirole & 27.83 & Economics & 70 & Simon Johnson & 13.90 & Economics \\
\hline 21 & Harold Demsetz & 27.69 & Economics & 71 & Albert A Cannella & 13.72 & Management \\
\hline 22 & April Klein & 27.18 & Finance & 72 & Donald C Hambrick & 13.59 & Management \\
\hline 23 & Robert E Hoskisson & 26.34 & Management & 73 & John J McConnell & 13.57 & Finance \\
\hline 24 & Steven M Shavell & 25.06 & Economics & 74 & Marcel Kahan & 13.49 & Law \\
\hline 25 & Ronald Gilson & 25.01 & Law & 75 & James A Brickley & 13.48 & Finance \\
\hline 26 & Ross Levine & 24.57 & Economics & 76 & Christine Jolls & 13.33 & Law \\
\hline 27 & Gerald F Davis & 23.12 & Management & 77 & Craig Doidge & 12.93 & Finance \\
\hline 33 & Dan R Dalton & 20.36 & Management & 83 & David F Larcker & 12.68 & Accounting \\
\hline 34 & William L Megginson & 20.23 & Finance & 84 & Tatiana Nenova & 12.67 & Economics \\
\hline 35 & Cass R Sunstein & 20.00 & Law & 85 & John Roberts & 12.59 & Management \\
\hline 36 & Karl V Lins & 19.99 & Finance & 86 & Hamid Mehran & 12.47 & Finance \\
\hline 37 & Paul A Gompers & 19.91 & Economics & 87 & W Gerard Sanders & 12.43 & Management \\
\hline 38 & Shaker A Zahra & 19.58 & Management & 88 & A Craig Mackinlay & 12.42 & Finance \\
\hline 39 & Jeffry Milton Netter & 19.13 & Economics & 89 & Philippe Aghion & 12.40 & Economics \\
\hline 40 & D Mike Wright & 19.10 & Economics & 90 & Larry H P Lang & 12.28 & Finance \\
\hline 41 & David Reeb & 18.89 & Management & 91 & Ruth Aguilera & 12.23 & Sociology \\
\hline 42 & David J Denis & 18.60 & Finance & 92 & Mara Faccio & 12.19 & Finance \\
\hline 43 & Reinier H Kraakman & 18.10 & Sociology & 93 & Leo E Strine & 12.14 & Law \\
\hline 44 & Kenneth Lehn & 18.00 & Economics & 94 & Lynn M LoPucki & 12.13 & Law \\
\hline 45 & Tarun Khanna & 17.77 & Economics & 95 & Daniel Wolfenzon & 12.05 & Economics \\
\hline 46 & Krishna Palepu & 17.50 & Management & 96 & Thorsten Beck & 12.02 & Economics \\
\hline 47 & Richard A Johnson & 16.98 & Management & 97 & Jeremy Stein & 11.83 & Economics \\
\hline 48 & Raghuram G Rajan & 16.94 & Finance & 98 & Laura T Starks & 11.83 & Finance \\
\hline 49 & Mike W Peng & 16.82 & Management & 99 & Todd Mitton & 11.79 & Economics \\
\hline 50 & Reva B Siegel & 16.79 & Law & 100 & Christian Leuz & 11.72 & Management \\
\hline
\end{tabular}


operationalized as a 0/1 variable where a "l" indicated male gender.

Our second control variable was Total Academic Experience. Previous literature has shown that academics early in their careers are generally more productive than academics later on in their careers (Chen et al., 2006; Goodwin \& Sauer, 1995; Hu \& Gill, 2000; Williamson \& Cable, 2003). Hence, we controlled for this variable as well. Total Academic Experience is operationalized as the number of years between the first academic appointment identified on the CV and 2008.

Our third control variable was whether the scholar served in an Academic Administrative Role, currently or previously. In general, academic administration prevents much research scholarship due to the demands of the administrative duties (Goodwin \& Sauer, 1995). Therefore, we controlled for this variable as well. Academic Administrative Experience was operationalized as a dummy variable where " 1 " indicated the scholar had served as a dean or a department chairperson.

Our fourth control variable was the amount of business experience possessed by the scholar (e.g., Lin \& Bozeman, 2006). The variable, Total Business Experience, is defined as the number of years of business experience mentioned on the CV. Our fifth control variable is the frequency of business consulting done by the scholar. Some observers argue that business consulting often leads to interdisciplinary insights (Perkman \& Walsh, 2008). As a result, we also controlled for this by creating a variable, Business Consulting Experience, which was measured by counting the number of consulting projects listed on the scholar's CV. Our sixth and final control variable, Articles, is the total number of articles published by the author and was collected by counting articles listed on the scholar's CV. Notably, we wanted to see if the quantity of articles published had any systematic relationship to the overall impact of the scholar's research program in corporate governance.

\section{RESULTS}

Table 3 presents the descriptive statistics and Table 4 presents the bivariate correlations. A test of variance inflation factors (VIF) indicated low mul-

TABLE 3

Descriptive Statistics: Overall Sample and Impact Group Subsamples

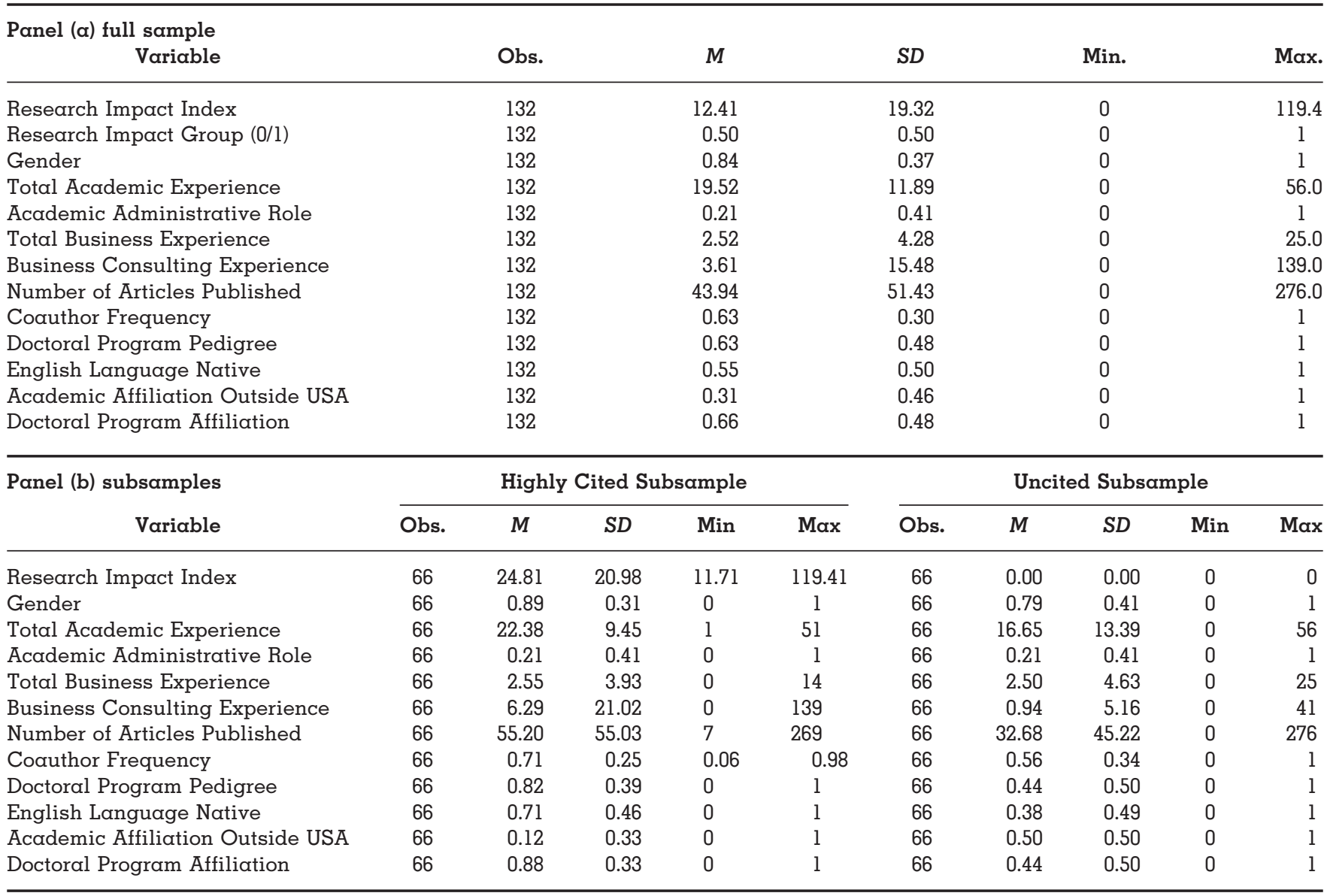


TABBLE 4

Bivariate Correlations $(N=132)$

\begin{tabular}{|c|c|c|c|c|c|c|c|c|c|c|c|c|c|c|}
\hline & Variable & 1 & 2 & 3 & 4 & 5 & 6 & 7 & 8 & 9 & 10 & 11 & 12 & 13 \\
\hline 1 & Research Impact Index & 1.00 & & & & & & & & & & & & \\
\hline 2 & Research Impact Group & 0.64 & 1.00 & & & & & & & & & & & \\
\hline 4 & Total Academic Experience & 0.22 & 0.24 & 0.22 & 1.00 & & & & & & & & & \\
\hline 5 & Academic Administrative Experience & -0.04 & 0.00 & -0.03 & 0.27 & 1.00 & & & & & & & & \\
\hline 6 & Total Business Experience & -0.08 & 0.01 & 0.09 & -0.19 & -0.03 & 1.00 & & & & & & & \\
\hline 9 & Coauthor Frequency & 0.16 & 0.24 & 0.21 & -0.19 & -0.05 & 0.09 & 0.14 & -0.02 & 1.00 & & & & \\
\hline 10 & Doctoral Program Pedigree & 0.32 & 0.39 & 0.05 & 0.18 & -0.06 & 0.00 & 0.08 & 0.07 & -0.07 & 1.00 & & & \\
\hline 11 & English Language Native & 0.07 & 0.33 & 0.02 & 0.34 & -0.01 & 0.21 & 0.12 & 0.16 & -0.03 & 0.34 & 1.00 & & \\
\hline 12 & Academic Affiliation Outside USA & -0.28 & -0.41 & 0.07 & -0.28 & 0.05 & -0.18 & -0.06 & -0.07 & 0.00 & -0.47 & -0.54 & 1.00 & \\
\hline 13 & Doctoral Program Affiliation & 0.25 & 0.46 & 0.21 & 0.17 & 0.02 & 0.08 & 0.11 & 0.12 & 0.19 & 0.21 & 0.11 & -0.21 & 1.00 \\
\hline
\end{tabular}

All correlations in bold are significant at $p<.05$.

ticollinearity with a mean value of all the variables equal to 1.41 , and the highest individual value of 1.90, which was well below the suggested value of 2 . Thus, we conclude that multicollinearity did not influence our results. Furthermore, we also checked for normality of our variables using Stata 10s Skewness Kurtosis test and found no problems with normality.

Table 5 presents the results of the logistic and OLS regressions with Research Impact Group (RIG) and Research Impact Index (RII) as the dependent variables, respectively. Models 1 and 3 examine control variables only, and Models 2 and 4 include controls and main effects for the logistic and OLS regressions. All four models have model significance, and Models 3 and 4, which include controls and main effects, show significant improvement over Models 1 and 2, which just contain control variables. Examining the control variables, none were significant with the exception of Total Academic Experience, where we found a positive, but marginally significant coefficient in the OLS regression $(\beta=0.28, p<.10)$.

The five hypotheses examined the impact of so-

TABLE 5

Regression Analysis on the Correlates of Research Impact $(N=132)$

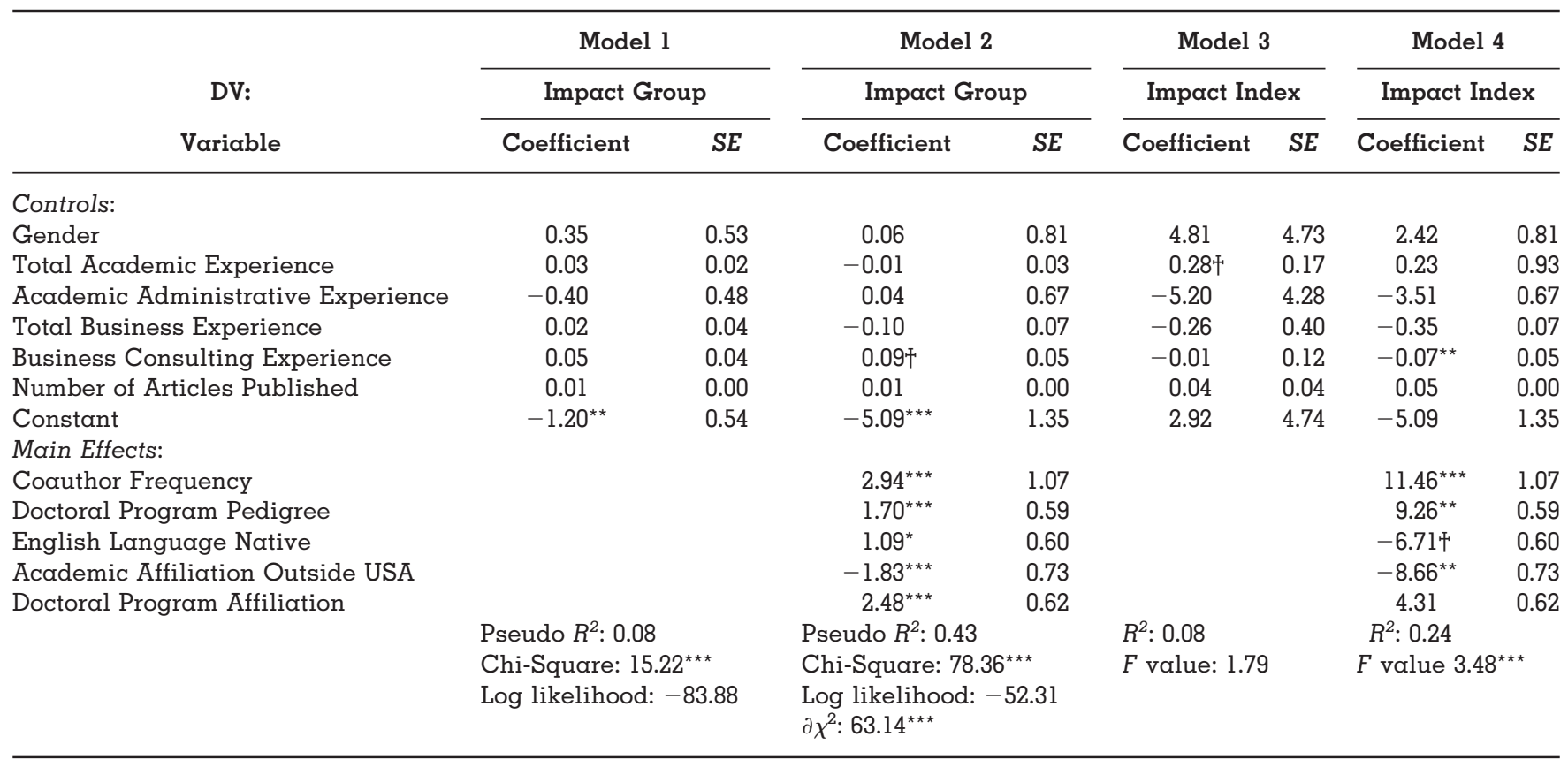

† $p<.10 .{ }^{*} p<.05 .{ }^{* *} p<.01 .{ }^{* * *} p<.001$. 
cial networks on corporate governance research impact. Hl posited that the frequency of coauthored articles would be positively associated with interdisciplinary research impact. This hypothesis was supported by the data in both logistic and OLS regressions, as the coefficients were positive and significant, as hypothesized (RIG Model 2: $\beta=2.94$, $p<.001$ and RII Model 4: $\beta=11.46, p<.001)$. H2 suggested that the pedigree of the doctoral program in which the scholor trained would be positively associated with interdisciplinary research impact. Both logistic and OLS regressions support H2, as the coefficients are positive and significant (RIG Model: $\beta=1.70, p<.001$ and RII Model: $\beta=9.26, p<.01$ ). H3 predicted that English language natives would be more impactful in corporate governance research. For both dependent variables, the hypothesized relationship was supported for the RIG measure, but was not supported for the RII measure. Thus, our third hypothesis was partially supported by our data. H4 suggested that scholars based at institutions located outside the United States would not be as impactful in their research as U.S.-based scholars. The coefficients are negative and significant (RIG Model: $\beta=-1.83, p<.01$ and RII Model: $\beta=-8.66, p<.05$ ), indicating support for H4. Finally, we examined the relationship between doctoral program affiliation and research impact in H5. Interestingly, we found relatively strong support for $\mathrm{H} 5$ in the logistic regression (RIG Model: $\beta=2.48, p<.001$ ), but not the OLS regression dealing with the RII measure.

\section{Robustness Tests}

To explore the robustness of our results, we altered our assumption that each coauthor in a cited research article contributed equally $(1 / n)$ in their citation credit. Following Allen and Dare (2009) as well as Boyd and colleagues (2005), nonalphabetical multiple author ordering was assumed to differentially signal scholar contributions. Of course, this assumption is somewhat suspect, since differential contributions that correspond exactly with alphabetical listing are missed. However, the occurrence of such a coincidence is presumed to be relatively unlikely.

Specifically, we altered the research impact index to weight the author's contributions as follows to reflect lead author contributions for nonalphabetical author listings. For nonalphabetical twoauthor publications, we awarded a $75 \%$ weighting for the first author and $25 \%$ for the second. For nonalphabetical three-author publications, we awarded a $60 \%$ weighting for first author, $30 \%$ for the second author, and $10 \%$ for the third author. For four or more nonalphabetical coauthored publications, we awarded $50 \%$ for the first author, $30 \%$ for the second, $20 \%$ for the third, and $10 \%$ for the fourth author.

With this recomputed research impact index, we found that our results were essentially identical even after changing our author credit assumption to reflect unequal contributions by multiple authors. These results suggest that the particular method for assigning author credit does not influence research impact in the long run, and that our new research impact measure is relatively robust.

\section{DISCUSSION}

We sought to identify the most influential scholars working in the interdisciplinary field of corporate governance and apply the social networking perspective to explain those results. We identified $a$ listing of the 100 top scholars based on a comprehensive and rigorous weighted index of citations over a 52-year study period which we called our Research Impact Index. This listing is unique based on its comprehensive approach, interdisciplinary nature, and global reach.

We also attempted to explain why these scholars were much more highly cited than other scholars who also published corporate governance research by creating an extreme variance sample of highly cited and uncited corporate governance scholars. The latter group was randomly selected from among the over 2,100 scholars who published corporate governance research during the study period, but their governance work was never cited in the SSCI database. In general, we found the social network variables do a good job of explaining the variance in scholarly citations in the field of corporate governance research. In other words, social networks appear to explain a considerable amount of variance in the citations rates of corporate governance scholarship.

Since corporate governance is inherently on interdisciplinary phenomenon, these results make sense. Due to the breadth of scholarship in corporate governance, social networks appear to be imperative to the success of this type of research. Whether it be coauthorship complementarities, specialized ties created by prestigious doctoral pedigrees, access to doctoral program networks, or affiliation with U.S.-based academic institutions with all their resources and connections worldwide, social networks appear to be essential for becoming a leading scholar in corporate governance research. This does not suggest that individual initiative does not matter, since individ- 
ual initiative may lead to one gaining access to privileged social networks; however, it does suggest that individual initiative is not sufficient to overcome the barriers associated with complex interdisciplinary fields like corporate governance.

These results do suggest that cutting-edge international interdisciplinary research will require the creation of or access to specialized social networks. For example, the Strategic Management Journal has stressed the importance of doing multicountry research studies (Bartlett \& Ghoshal, 1991). This implies that to perform a multicountry empirical study, researchers will need to either have access to large funding sources, such as the Global Leadership and Organizational Behavior Effectiveness (GLOBE) study (e.g., House, Hanges, Javidan, Dorfman, \& Gupta, 2004), or they will need to create an informal social network to overcome institutional barriers, such as the cross-cultural research done by multinational research teams (e.g., Ralston, Egri, de la Garza, \& Ramburuth, 2009). In either case, an extensive international social network appears to be essential for conducting high-impact interdisciplinary research.

\section{Limitations}

While our ranking methodology represents on improvement over previous efforts, it has some limitations that need to be noted. First, we assigned one quarter credit to articles with more than three named authors without actually knowing the number of scholars per paper. This could give more citation credit to authors who write in larger teams of coauthors than may be earned. Hence, future researchers might want to address this limitation in our data by investigating author lists that go beyond the Web of Science database.

Second, we only considered citations published in the SSCI database within Thomson Reuters "Web of Science." While the list of published entities is mainly articles, there are some book reviews and other types of documents that are included in citation impact. Thus, some nonpeer-reviewed articles could be driving up author citation rates, and it is unknown to what extent that this could alter our results. A recent study by Meho and Yang (2007) discusses the advantages and disadvantages of using the Web of Science, which we used here, or the alternatives data sources of Scopus or Google Scholar.

Third, our study relied on data acquired by way of content analysis of CVs and, thus, we were limited to demographic proxies as sources of predictors of research impact. There is still much to be learned about the drivers of research impact, and survey studies or field interviews that attempt to gauge more than just demographic data would be of great interest. For example, our theoretical argument that social connections created may be more important than actual training received in one's doctoral education merits further study to tease out the actual contribution of each to a scholar's subsequent research impact.

Fourth, our study was limited to one area of multidisciplinary research, namely, corporate governance. Future researchers may uncover additional insights about other areas of multidisciplinary research impact, such as strategic alliances, foreign subsidiary dynamics, strategic leadership, or corporate social responsibility. Finally, we assume that highly cited research is impactful research, similar to much previous bibliometric research. As Argyris (1996) argues, however, the most impactful research is not just cited, it is applied to actual business problems. While we agree with this critique, this application issue is beyond the practical scope of this study. Nonetheless, this is an opportunity for future research.

\section{CONCLUSIONS AND IMPLICATIONS}

Despite the limitations identified above, this study is able to make a novel and important contribution to the sociology of knowledge literature. It is noteworthy for scholars, as it provides evidence that building social networks is vitally important to one's career and to increasing one's chances of success in academic publishing, particularly with respect to publishing in interdisciplinary areas, such as corporate governance. First and foremost, any candidate considering entering into a doctoral program should be concerned with getting accepted by a top-tier PhD program in order to fully leverage those social networks. Second, our findings suggest that scholars should not try to publish as a single author, particularly in interdisciplinary research studies. Our data suggest that scholars will be much more impactful if they seek out coauthorship opportunities. Last, despite the growth and credibility of higher education options outside the United States, scholars still see increased benefits to their research impact when affiliated with U.S.-based institutions of higher learning.

This study is also useful for university administrators who need to recognize that faculty need to build and maintain social networks in order to enhance their research impact. Administrators should consider increasing networking opportunities for faculty, such as increasing conference travel funding and encourage sabbaticals at U.S.based universities for scholars not affiliated with 
U.S.-based institutions. In addition, our comprehensive methodology for tracking the cited publications of a wide variety of scholars offers insights for documenting research impact for evaluation purposes. In closing, this study has provided some new insights into interdisciplinary research impact and we hope that our efforts will encourage others to expand on this body of work.

\section{REFERENCES}

Adler, N. J., \& Harzing, A.-W. 2009. When knowledge wins: Transcending the sense and nonsense of academic rankings. Academy of Management Learning and Education, 8: 72-82.

Allen, M. T., \& Dare, W. H. 2009. Evaluating co-author contributions in real estate research. Journal of Real Estate Practice and Education, 12: 33-42.

Antonakis, J., \& Lalive, R. 2008. Quantifying scholarly impact: IQp versus the Hirsch h. Journal of the American Society for Information Science and Technology, 59: 956-969.

Argyris, C. 1996. Unrecognized defenses of scholars: Impact on theory and research. Organization Science, 7: 79-87.

Barbezat, D., \& Hughes, J. W. 2001. The effect of job mobility on academic salaries. Contemporary Economic Policy, 19: 409423.

Barnes, J. 1954. Class and committees in a Norwegian island parish. Human Relations, 7: 39-58.

Bartlett, C. A., \& Ghoshal, S. 1991. Global strategic management: Impact on the new frontiers of strategy research. Strategic Management Journal, 12: 15-16.

Bartunek, J. 2007. Academic-practitioner collaboration need not require joint or relevant research: Toward a relational scholarship of integration. Academy of Management Journal, 50: 1323-1327.

Bazley, J. D., \& Nikolai, L. A. 1975. The organizational set prestige ranking and its impact upon accounting department faculties. Accounting Review, 50: 881-888.

Bedian, A., Cavazos, D., Hunt, J. G., \& Jauch, L. 2010. Doctoral degree prestige and the academic marketplace: A study of career mobility within the management discipline. Academy of Management Learning and Education, 9: 11-25.

Belliveau, M. 2005. Blind ambition? The effects of social networks and institutional sex composition on the job search outcomes of elite coeducational and women's college graduates. Organization Science, 16: 134-150.

Bergh, D. H., Perry, J., \& Hanke, R. 2006. Some predictors of SM] article impact. Strategic Management Journal, 27: 81-100.

Boyd, B., Finkelstein, S., \& Gove, S. 2005. How advanced is the strategy paradigm? The role of particularism and universalism in shaping research outcomes. Strategic Management Journal, 26: 841-854.

Brown, L. D., \& Gardner, J. C. 1985. Applying citation analysis to evaluate the research contributions of accounting faculty and doctoral programs. Accounting Review, 60: 262.

Bruce, A., Lyall, C., Tait, J., \& Williams, R. 2004. Interdisciplinary integration in Europe: The case of the fifth framework programme. Futures, 36: 457-477.
Burris, V. 2004. The academic caste system: Prestige hierarchies in $\mathrm{PhD}$ exchange networks. American Sociological Review, 69: 239-264.

Burt, R. S. 1982. Toward a structural theory of action: Network models of social structure, perception, and action. New York: Academic Press.

Cantwell, J., \& Brannen, M. J. 2011. Positioning JIBS as an interdisciplinary journal. Journal of International Business Studies, 42: 1-9.

Carillo, M., Papagni, E., \& Capitanio, F. 2008. Effects of social interactions on scientists' productivity. International Journal of Manpower, 29: 263-279.

Carpenter, M. A. 2009. An executive's primer on the strategy of social networks. New York: Business Expert Press.

Carter, C., Ellram, L., \& Tate, W. 2007. The use of social network analysis in logistics research. Journal of Business Logistics, 28: 137-170.

Chan, K. C., Chen, C. R., \& Fung, H. 2009. Pedigree or placement? The research productivity in finance. Financial Review, 44: 87-111.

Chan, K. C., Chen, C. R., \& Steiner, T. L. 2004. Who is publishing? An analysis of finance research productivity in the European region. Journal of Business Finance \& Accounting, 31: 401-437.

Chen, Y., Gupta, A., \& Hoshower, L. 2006. Factors that motivate business faculty to conduct research: An expectancy theory analysis. Journal of Education for Business, 81: 179-189.

Cheng, J., Henisz, W., Roth, K., \& Swaminathan, A. 2009. Advancing interdisciplinary research in the field of international business: Prospects, issues and challenges. Journal of International Business Studies, 40: 1070-1074.

Chermack, T., \& Lynham, S. A. 2002. Assessing institutional sources of scholarly productivity in human resource development from 1995 to 2001. Human Resource Development Quarterly, 13: 34l-346.

Cole, S., \& Cole, J. R. 1967. Scientific output and recognition: A study in the operation of the reward system in science. American Sociological Review, 32: 377-390.

Cronin, B., \& Meho, L. 2006. Using the h-index to rank influential information scientists. Journal of the American Society for Information Science and Technology, 57: 1275-1285.

Daft, R., Griffin, R., \& Yates, V. 1987. Retrospective accounts of research factors associated with significant and not-sosignificant research outcomes. Academy of Management Journal, 30: 763-785.

Dao, M. Q. 2004. Rural poverty in developing countries: An empirical analysis. Journal of Economic Studies, 31: 500520.

Davis, J., Huston, J., \& Patterson, D. 2001. The scholarly output of economists: A description of publishing patterns. Atlantic Economic Journal, 29: 341-349.

Diamantopoulos, A. 1996. A model of publication performance of marketing academics. International Journal of Research in Marketing, 13: 163-180.

Fleming, L., King, C., \& Juda, A. 2007. Small worlds and regional innovation. Organization Science, 18: 938-956.

Fogarty, T., \& Ruhl, J. 1997. Institutional antecedents of accounting foculty research productivity: A LISREL study of the "best and brightest." Issues in Accounting Education, 12: 27-48. 
Fox, K. J., \& Milbourne, R. 1999. What determines research output of academic economists? Economic Record, 75: 256-267.

Friedman, R., Kane, M., \& Cornfield, D. 1998. Social support and career optimism: Examining the effectiveness of network groups among black managers. Human Relations, 51: 11551178.

Gallivan, M. J., \& Benbunan-Fich, R. 2007. Analyzing IS research productivity: An inclusive approach to global IS scholarship. European Journal of Information Systems, 16: 36-53.

Garfield, E. 1977. The 250 most-cited primary authors, 1961-1975. part 3. Each author's most-cited publication. Current Contents, 51: 5-20.

Goodwin, T., \& Sauer, R. 1995. Life cycle productivity in academic research: Evidence from cumulative publication histories of academic economists. Southern Economic Journal, 61: 728-743.

Gomez-Mejia, L. R., \& Balkin, D. B. 1992. The determinants of faculty pay: An agency theory perspective. Academy of Management Journal, 35: 921-955.

Graffy, E. 2008. Meeting the challenges of policy-relevant science: Bridging theory and practice. Public Administration Review, 68: 1087-1103.

Greve, A., \& Salaff, J. 2003. Social networks and entrepreneurship. Entrepreneurship: Theory and Practice, 28: 1-20.

Hammermesh, D., \& Oster, S. 2002. Tools or toys? The impact of high technology on scholarly productivity. Economic Inquiry, 40: 539-555.

Heck, J., \& Zaleski, P. 1991. Trends in economic-journal literature: 1969-89. Atlantic Economic Journal, 19: 27-32.

House, R. J., Hanges, P. J., Javidan, M., Dorfman, P. W., \& Gupta, V. 2004. Culture, leadership, and organizations: The GLOBE study of 62 societies. Thousand Oaks: Sage Publications.

Hsieh, P., \& Chang, P. 2009. As assessment of world-wide research productivity in production and operations management. International Journal of Production Economics, 120: 540-555.

Hu, Q., \& Gill, T. G. 2000. IS faculty research productivity: Influential factors and implication. Information Resources Management Journal, 13: 15-25.

Jacobs, J., \& Frickel, S. 2009. Interdisciplinarity: A critical assessment. Annual Review of Sociology, 35: 43-65.

Jarley, P., Chandler, T., \& Faulk, L. 1998. Are we playing the same game? Publishing task environments and research productivity among management specialists. Human Relations, 51: 799-824.

Judge, T. A., Cable, D. M., Colbert, A. E., \& Rynes, S. L. 2007. What causes a management article to be cited-Article, author or journal? Academy of Management Journal, 50: 491-506.

Judge, W. Q. 2009. The complexity of international corporate governance research. Corporate Governance: An International Review, 17: 525.

Judge, W. Q., Filatotchev, I., \& Aguilera, R. 2010. Comparative corporate governance and international business research. Corporate Governance: An International Review, 18: 493495.

Labianca, G., \& Brass, D. 2006. Exploring the social ledger: Negative relationships and negative asymmetry in social networks in organizations. Academy of Management Review, 31: 596-616.
Landis, J. R., \& Koch, G. G. 1977. The measurement of observer agreement for categorical data. Biometrics, 33: 158-174.

Leahey, E. 2007. Not by productivity alone: How visibility and specialization contribute to academic earnings. American Sociological Review, 72: 533-561.

Lee, A. 1999. Rigor and relevance in MIS research: Beyond the approach of positivism alone. MIS Quarterly, 23: 29-34.

Lin, M., \& Bozeman, B. 2006. Researchers' industry experience and productivity in university-industry research centers: A "scientific and technical human capital" explanation. Journal of Technology Transfer, 31: 269-290.

Lorsch, J. 2009. Regaining lost relevance. Journal of Management Inquiry, 18: 108-114.

Manning, L. M., \& Barrette, J. 2005. Research performance management in academe. Canadian Journal of Administrative Sciences, 22: 273-287.

Marsh, S. J., \& Hunt, C. S. 2006. Not quite as simple as A-B-C: Reflections on one department's experiences with publication ranking. Journal of Management Inquiry, 15: 301-315.

Maske, K., Durden, G., \& Gaynor, P. 2003. Determinants of scholarly productivity among male and female economists. Economic Inquiry, 41: 555-564.

Mathieu, R., \& McConomy, B. J. 2003. Productivity in "top-ten" academic accounting journals by researchers at Canadian universities. Canadian Accounting Perspectives, 2: 43-76.

McDowell, J. M., \& Smith, J. K. 1992. The effect of gender-sorting on propensity to coauthor: Implications for academic promotion. Economic Inquiry, 30: 68-82.

McWilliams, A., Siegel, D., \& Van Fleet, D. 2005. Scholarly journals as producers of knowledge: Theory and empirical evidence based on data envelopment analysis. Organizational Research Methods, 8: 185-201.

Medoff, M. H. 1996. A citation-based analysis of economists and economics programs. American Economist, 40: 46-56.

Meho, L. I., \& Sonnenwald, D. H. 2000. Citation ranking versus peer evaluation of senior faculty research performance: A case study of Kurdish scholarship. Journal of the American Society for Information Science, 51: 123-133.

Meho, L., \& Yang, K. 2007. Impact of data sources on citation counts and rankings of LIS faculty: Web of science versus Scopus and Google Scholar. Journal of the American Society for Information Science and Technology, 58: 2105-2125.

Money, R. B. 1998. International multilateral negotiations and social networks. Journal of International Business Studies, 29: 695-711.

Moore, W., Newman, R., \& Turnbull, G. 2001. Reputational capital and academic pay. Economic Inquiry, 39: 663-671.

Morrisey, M., \& Cawley, J. 2007. The production of published research U.S. academic health economists. International Journal of Health Care Finance, 8: 87-111.

Perkman, M., \& Walsh, K. 2008. Engaging the scholar: Three types of academic consulting and their impact on universities and industry. Research Policy, 37: 1884-1891.

Pfeffer, J., \& Langton, N. 1993. The effect of wage dispersion on satisfaction, productivity, and working collaboratively: Evidence from college and university faculty. Administrative Science Quarterly, 38: 382-407.

Piotrowksi, C., Watt, J., \& Armstrong, T. 2010. The interdisciplinary nature of the field of crisis management: A call for 
research collaboration. Organization Development Journal, 28: 87-93.

Polonsky, M., \& Ringer, A. C. 2009. The global and regional dispersion of publishing in the field of international marketing. Journal of Global Marketing, 22: 155-172.

Prasad, R., \& Prasad, S. B. 2009. Output versus salient impact in financial economics. Applied Financial Economics, 19: 1697-1712.

Ralston, D., Egri, C., de la Garza, M., Ramburuth, P. et al. 2009. Ethical preferences for influencing superiors: A 41-society study. Journal of International Business Studies, 40: 10221045.

Robinson, L. M., \& Adler, R. 1981. Measuring the impact of marketing scholars and institutions: An analysis of citation frequency. Academy of Marketing Science Journal, 9: 147-167.

Sabrin, M. 2002. A ranking of the most productive business ethics scholars: A five-year study. Journal of Business Ethics, 36: 355-379.

Seggie, S., \& Griffith, D. 2009. What does it take to get promoted in marketing academia? Understanding exceptional publication productivity in leading marketing journals. Journal of Marketing, 73: 122-132.

Shanghai Jiao Tung University. 2010. Academic ranking of worldwide universities-2009. http://www.arwu.org/ ARWU2009.jsp.

Silver, E. A. 2008. Some ideas on enhancing research productivity. International Journal of Production Economics, 118: 352360.

Smith, J., Fox, G., Park, S., \& Lee, L. 2008. Institutional antecedents to research productivity in operations: The U.S. perspective. International Journal of Operations and Production Management, 28: 7-26.
Treviño, L. J., Mixon, F. G., Jr., Funk, C. A., \& Inkpen, A. C. 2010. A perspective on the state of the field: International business publications in the elite journals as a measure of institutional and faculty productivity. International Business Review, 19: 378-387.

Truex, D., Takeda, H., \& Cuellar, M. 2009. Assessing scholarly influence: Using the Hirsch indices to reframe the discourse. Journal of Association of Information Systems, 10: 560-594.

Williamson, I., \& Cable, D. 2003. Predicating early career research productivity: The case of management faculty. Journal of Organizational Behavior, 24: 25-44.

Woodside, A. 2009. Journal and author impact metrics: An editorial. Journal of Business Research, 62: 1-4.

Worrell, D. 2009. Assessing business scholarship: The difficulties in moving beyond the rigor-relevance paradigm trap. Academy of Management Learning and Education, 8: 127130.

Wright, B. 2011. Public administration as an interdisciplinary field: Assessing its relationship with the fields of law, management, and political science. Public Administration Review, 71: 96-101.

Xu, S., Yalcinkaya, G., \& Seggie, S. 2008. Prolific authors and institutions in leading international business journals. Asia Pacific Journal of Management, 25: 189-207.

Yang, Z., Jaramillo, F., \& Chonko, L. 2010. Productivity and coauthorship in JPSSM: A social network analysis. Journal of Personal Selling and Sales Management, Winter: 47-71.

Zahra, S., \& Newey, L. 2009. Maximizing the impact of organization science: Theory-building at the intersection of disciplines. Journal of Management Studies, 46: 1059-1075.

William Q. Judge is the E.V. Williams Professor of Strategic Leadership at Old Dominion University. He earned his MBA and PhD degrees at the University of North Carolina at Chapel Hill. His current research interests focus on strategic leadership processes, comparative corporate governance, and organizational change and innovation.

Thomas Weber is a $\mathrm{PhD}$ candidate at Old Dominion University. He earned his MBA at Old Dominion University and his Master's of Engineering at the University of Louisville. His research interests are in the areas of the strategic change process, organizational culture, and technological innovation.

Maureen I. Muller-Kahle is an assistant professor of business at the Pennsylvania State University, York. She earned her MBA at the University of Massachusetts, Amherst and her $\mathrm{PhD}$ at Old Dominion University. Her research interests are in the area of corporate governance and strategic leadership. 